\title{
Terra Brasilis
}

Revista da Rede Brasileira de História da Geografia e Geografia Histórica

\section{$15 \mid 2021$}

Políticas e geopolíticas de tradução

\section{Descanonização e descolonialização de clássicos e canônicos na geografia brasileira e internacional}

Decanonisation and decolonisation of classics and canonics in Brazilian and international geography

Décanonisation et décolonisation de classiques et canoniques dans la géographie brésilienne et internationale

Descanonización y descolonización de clásicos y cánones en la geografía brasileña e internacional

\section{Guilherme Ribeiro}

\section{OpenEdition}

\section{Journals}

\section{Edição electrónica}

URL: https://journals.openedition.org/terrabrasilis/9173

DOI: 10.4000/terrabrasilis.9173

ISSN: 2316-7793

Editora

Rede Brasileira de História da Geografia e Geografia Histórica

Refêrencia eletrónica

Guilherme Ribeiro, «Descanonização e descolonialização de clássicos e canônicos na geografia brasileira e internacional», Terra Brasilis [Online], 15 | 2021, posto online no dia 31 julho 2021 consultado o 05 dezembro 2022. URL: http://journals.openedition.org/terrabrasilis/9173 ; DOI: https:// doi.org/10.4000/terrabrasilis.9173

Este documento foi criado de forma automática no dia 5 dezembro 2022.

All rights reserved 


\title{
Descanonização e descolonialização de clássicos e canônicos na geografia brasileira e internacional
}

\author{
Decanonisation and decolonisation of classics and canonics in Brazilian and \\ international geography \\ Décanonisation et décolonisation de classiques et canoniques dans la géographie \\ brésilienne et internationale \\ Descanonización y descolonización de clásicos y cánones en la geografía \\ brasileña e internacional
}

Guilherme Ribeiro

\section{NOTA DO AUTOR}

Innes Keighren, Christian Abrahamsson e Veronica della Dora foram desde o início simpáticos à recepção de seu artigo para o português, sendo que Innes ainda teve paciência e generosidade em driblar a burocracia para que a versão brasileira pudesse circular legalmente entre nós. Nesse sentido, somos gratos também a Reuben RoseRedwood, editor da Dialogues in Human Geography. Meu aluno e bolsista Marcos Vinícius Fernandes Gonçalves (UFRRJ) foi um interlocutor tão aplicado que acabou por traduzir On canonical geographies para o idioma de Conceição Evaristo. Aproveito para parabenizá-lo e agradecê-lo pela iniciativa, bem como aos colegas que aceitaram participar dessa seção. Esse texto integra nosso projeto "Centro de cálculo, redes de circulação e história da geografia: o caso da Revista Brasileira de Geografia do IBGE (1939-1996)", contemplado pelo edital Faperj Apoio a Grupos Emergentes de Pesquisa no Estado do Rio de Janeiro em 2019.

1 Fundada no ano de 2011 por Rob Kitchin (National University of Ireland Maynooth), a proposta da revista de língua inglesa Dialogues in human geography é a de publicar textos 
provocativos acompanhados das reações por eles suscitadas. Trata-se de um estímulo a discussões imediatas e plurais, um exercício o qual, ao requerer abertura de espírito, franqueza e generosidade por parte de autores e comentaristas, está bem longe do modus operandi personalista dominante na sociedade brasileira - cordial à la Buarque de Holanda quase um século após seu diagnóstico (Buarque de Holanda, 2006 [1936]) e, consequentemente, entre seus geógrafos. A ausência de um debate mais franco e horizontal entre nós revela-se, por exemplo, na inexistência de resenhas como gênero de escrita e problematização dos livros. Afinal, em um campo intelectual germinado pelo populismo e pelo clientelismo, uma resenha minimamente negativa sobre um pesquisador reconhecido certamente cairia mal não para o autor da obra, mas para o resenhista... Aqui, aproveitamos a ocasião para antecipar nossa definição de canônico: canônico não é apenas o que tem sido distorcido ou abordado superficialmente, mas o que tem sido, de um lado, alçado à condição de intocável por seu capital simbólico (Bourdieu, 2006 [1989], 2004 [1997]) e, portanto, replicado de maneira automática e acrítica; de outro lado, simplesmente silenciado ou como se não existisse ou como se certa interpretação tivesse encerrado de vez a questão.

2 Foi imbuído desse espírito que acolhemos a sugestão do editor permanente Rafael Augusto Andrade Gomes de inaugurar no presente dossiê uma seção capaz de debater trabalhos cujas argumentações possuam impacto mais geral que pontual sobre a história da geografia e a geografia histórica. Assim, além de verter On canonical geographies do inglês para o português - para a língua brasileira, sendo mais exato, já que tanto a grafia quanto o jeito de escrever são diferentes em relação a Portugal -, cabe levantarmos algumas observações a respeito de seu conteúdo e de como ele pode iluminar determinadas características da história da geografia consumida e produzida no Brasil.

3 Um dos principais méritos de On canonical geographies reside em ter sido concebido por autores de três nacionalidades e idiomas diferentes: o irlandês Innes M. Keighren, a italiana Veronica della Dora e o sueco Christian Abrahamsson. Mobilizando trânsitos e tradições intelectuais distintas porém convergentes rumo à geografia anglo-saxã (os dois primeiros são radicados na Inglaterra), tais experiências lhes tornaram mais sensíveis à necessidade de repensar, abrir, deslocar um pouco a história da geografia. Outro aspecto a ser considerado diz respeito ao fato de que, compreendidos na faixa dos quarenta anos, os três pertencem a uma geração cuja marca dos questionamentos provocados pela globalização à produção científica do "Norte Global" é incontornável muito embora não haja nem adesão nem referência por parte deles ao pensamento decolonial, por exemplo. Ainda que não mencionadas literalmente, sobreponhamos à atmosfera mais ampla na qual emergiu o artigo o florescimento das abordagens anglosaxãs ligadas à sociologia e à história da ciência sob o prisma espacial (Latour 1987; Ophir \& Shapin 1991; Secord 2004) e, notadamente, àquelas relativas à mobilidade, circulação e geografia do conhecimento responsáveis por sublinhar o papel das escalas, redes e deslocamentos científicos (Livingstone, 2003; Naylor, 2005; Meusburger et al., 2010; Jöns et al., 2017 [para citar apenas alguns]).

Uma vez que o principal argumento do texto consiste em interrogar, digamos, uma certa imagem, uma representação ou, mesmo, um inconsciente coletivo - com a permissão de flexibilizar um pouco o espectro da questão - sobre o legado textual da história da geografia humana a partir dos processos de desvalorização [disparage], exaltação [exalting], lembrança [remembering] e esquecimento [forgetting] (Keighren et 
al., 2012: 296), em um Academia intelectualmente francófona como a brasileira (do ponto de vista das Humanidades, grife-se) o que nos vêm à mente é que tais processos formaram o cerne da aula inaugural de Michel Foucault no Collège de France em 1970. Tal como a interpretamos, a ordem discursiva constituinte dos saberes é um jogo de inclusão-exclusão de temas, conceitos, autores e métodos cujas regras não necessariamente obedecem ao rigor e à transparência em nome de uma suposta verdade intocada e sacralizada, mas à repetição e consagração de certas ideias em detrimento de outras. Assim, grupos, revistas, livros e instituições operam de modo a fixar e a difundir suas agendas determinando o que é e não é geográfico, científico, artístico, literário e ficcional com tamanho vigor a ponto de naturalizar ou, melhor dizendo, canonizar o que de fato são elaborações sociais atravessadas pelas dimensões do poder e da política. Neste movimento, o filósofo francês reorienta suas atenções não para o que está consolidado ocupando o centro, mas para o que foi preterido e habita nas margens - e, desta forma, abre caminhos para um exame crítico da razão moderna (Foucault, 1971 [1970]).

5 Embora não apareça nas referências, é mais que plausível imaginar que em algum momento de suas carreiras Keighren, Abrahamsson e della Dora tenham se deparado com A ordem do discurso - cujas primeiras traduções em inglês, italiano e sueco datam respectivamente de 1971, 1972 e 1993 (Foucault, 1971 [1970], 1972 [1970], 1993 [1970]) -, muito embora o tom da bibliografia e da argumentação nos levem a sugerir que a inspiração deles esteja associada a algo mais historiográfico que filosófico ou teórico. É neste sentido que a distinção entre clássicos e canônicos deve ser compreendida. Os primeiros foram definidos como os que "exerceram papel de destaque na moldagem da disciplina geografia e que permanecem intelectual ou pedagogicamente importantes hoje; que dialogaram com suas épocas mas que também enxergaram adiante; textos cujas mensagens transcendem modas e tendências intelectuais passageiras. Em outras palavras, textos 'fundacionais' que continuamos a usar em nossas pesquisas e no ensino independente de quando e onde foram escritos - textos que, conscientemente ou não, nós escolhemos lembrar" (Keighren et al., 2012: 299, minha tradução). Por outro lado, canônicos também "têm sido centrais na moldagem da disciplina mas, diferente dos clássicos, não necessariamente continuam a conversar de forma significativa com o presente. Inspirados por Fishelov (2010), são textos que perderam sua função ou capacidade dialógica. Nesse sentido, a um clássico é atribuída uma aura de imortalidade, enquanto um texto canônico é entendido como uma lembrança de uma época passada a qual não necessariamente desejamos retornar" (idem, p.300, minha tradução).

6 Aberta a discussão, digamos o seguinte: o que parece uma dicotomia pode muito bem operar de modo complementar. Se por sua contribuição à institucionalização universitária e à teorização sobre a geografia humana dificilmente Vidal de la Blache teria seu status de clássico contestado, isto não o blinda de, ao ter seu pensamento reduzido a uma abordagem descritiva, regionalista e possibilista - recebendo no Brasil o desafortunado rótulo de "tradicional" como identificação de algo ultrapassado -, ser canonizado. Sua definição de geografia como ciência dos lugares e não dos homens não foi elaborada a contento por seus interlocutores, mas canonizada em vários contextos $\mathrm{e}$ de acordo com interesses que em muito se distanciavam de um exame equilibrado de sua obra (Ribeiro 2020a). Esboçada em linhas gerais, a canonização indica que uma dada referência intelectual passou por um processo de simplificação baseado essencialmente 
em uma triagem inconsistente de seus textos. Porém, embora incompatível com seu legado, nem por isso deixou de ser legitimada pelo campo.

7 Foi nesta direção que encaminhamos o seguinte diagnóstico na apresentação da nossa coletânea Vidal, Vidais: "De modo geral podemos dizer que a história do pensamento geográfico canonizou a Geografia vidaliana, ao reduzi-la a uma única versão, pautada em alguns poucos artigos (...). Assim, se quisermos compreender com mais clareza e amplidão a herança geográfica de Vidal de la Blache, é necessário 'descanonizá-lo', isto é, interpretar sua reflexão a partir de seu caráter dinâmico e múltiplo (daí o 'Vidais' no título desse livro) - aspecto dado também pelo contexto histórico e o diálogo travado pelo autor com seu tempo (...). Por essas e outras razões, cremos que a Geografia vidaliana, com todas as suas idas e vindas, representou uma perspectiva científica de vanguarda no ambiente intelectual francês na virada do século XIX para o XX, proporcionando, ainda hoje, releituras e debates importantes - como costuma ocorrer com todo autor a merecer o adjetivo "clássico"' (Ribeiro et al., 2012: 13-15).

8 A semelhança de vocábulos e intenções está longe de ser casual, e constatar esse gênero de Zeitgeist - artigo e livro foram publicados no mesmo ano de 2012 - pode ser um sinal de que convergências como essa tornem-se cada vez mais comuns em tempos de mundialização da produção geográfica. Afinal, a correspondência entre escala nacional e pensamento social típica da emergência das ciências humanas e consolidada no transcorrer do século passado vem sendo erodida tanto na prática quanto na teoria (Ortiz, 1994) desde, pelo menos, a descolonização nas décadas de 1960 e 1970 e, com o impulso da globalização, a noção de transnacional - não obstante suas imprecisões entra em cena e acaba mesmo por aproximar o que outrora não passariam de comparações entre "Escolas Nacionais de Geografia" (sobre os limites das metodologias comparativas, ver Werner \& Zimmermann, 2004).

9 Entre nós, Introdução à geografia: geografia e ideologia (Sodré, 1976); O que é Geografia? (Moreira, 1980); Geografia: pequena história crítica (Moraes, 1995 [1981]); e Geografia, ciência da sociedade: uma introdução à análise do pensamento geográfico (Correia de Andrade, 1987), pioneiros livros de história da geografia publicados sob inspiração marxista entre o final dos anos de 1970 e 1980 - não existiam obras dessa natureza redigidos por brasileiros durante todo o século XX até onde sabemos, o que não significa dizer que não houve uma produção de artigos sobre teoria, métodos e conceitos nas páginas de periódicos como o Boletim Geográfico e a Revista Brasileira de Geografia, por exemplo -, são exemplares perfeitos de canonização (muito embora críticos), posto que alçados à condição de inquestionáveis e citados amiúde sem muito rigor. Compostos por fórmulas fáceis e ligeiras marcadas por alto grau de generalização e ensaísmo, sua penetração em artigos, eventos e nos cursos de introdução e história da geografia Brasil afora - cursos estes ainda improvisados por geógrafos especialistas em outras áreas - continua até hoje. O contraste deles com Filosofía y ciencia en la geografía contemporánea do espanhol Horacio Capel (1981), o qual veio à luz no mesmo contexto, sob semelhante inspiração teórico-política e circulou um pouco entre nós, salta aos olhos de qualquer leigo. Entretanto, e a despeito da proximidade da língua castelhana com a portuguesa, o tour de force de Capel foi absolutamente deslocado pelos cânones nacionais acima listados.

Enfim, se compartilhamos com Keighren, Abrahamsson e della Dora os esforços visando ampliar e pluralizar as maneiras de contar a história da geografia e se os conceitos de clássico e canônico foram por eles recuperados exatamente para serem problematizados, é fundamental acentuar tanto a geograficidade quanto a historicidade inerentes a toda 
e qualquer tentativa de escrever história da geografia. A repetição de palavras é absolutamente intencional e pretende ressaltar que nenhum discurso pode prescindir nem do tempo nem do espaço. Do orientalismo de Said ao pensamento fronteiriço [border thinking] de Mignolo e à provincialização da Europa por Chakrabarty, do ponto de vista progressista o que está em jogo na incorporação do lugar ao estudo dos saberes é a dimensão geopolítica inscrita em suas dinâmicas de produção e disseminação (Said, 1990 [1978]; Mignolo, 2000; Chakrabarty, 2008 [2000]). Portanto, é inconcebível estudar Vidal de la Blache sem levar em conta sua filiação francesa e tudo o que ela representa em termos do caldo de cultura que o formou como intelectual. Todavia, considerar o lugar não significa, evidentemente, aderir a qualquer raciocínio determinista. Muito pelo contrário, permite discernir com mais clareza como Reclus, conterrâneo e contemporâneo de Vidal de la Blache, optou por uma via política e teórica antípoda. Isto mostra que o nacionalismo e o imperialismo, por exemplo, não são escolhas "de uma época" como se houvesse um determinismo histórico a atrelar obrigatoriamente os sujeitos a um dado padrão, mas fenômenos sociais cujas inclinações políticas fizeram com que Reclus os impugnasse e Vidal de la Blache os chancelasse. Ou seja, enunciar o lugar é uma estratégia metodológica de primeira grandeza, pois significa revelar tanto a geograficidade da ciência como campo de tensão e de disputa quanto a possibilidade de historicizar fenômenos de maneiras diferentes. Afinal, a dita Escola Francesa de Geografia consagrada mundo afora não foi a de Reclus, mas a de Vidal, e, com ela, uma certa concepção de França, de Europa, de mundo, de sociedade, de ensino... Ao abrimos mão de desvendar os espaços e suas geopolíticas constituintes da produção científica, estaremos tão somente fortalecendo a perspectiva canônica que queremos criticar. Se tal raciocínio estiver correto, então afirmações segundo as quais "textos fundacionais" independem de "quando e onde foram escritos" (Keighren et al., 2012: 299) devem ser reavaliadas com urgência.

11 No mesmo diapasão, embora concordemos com o fato de que clássicos assim são denominados, entre outras razões, por sua capacidade de transcendência, com suas obras atravessando e influenciando gerações, a "aura de imortalidade" (Keighren et al., 2012: 300) a eles atribuída não pode ser confundida em nenhum momento com uma interpretação a-histórica dos mecanismos de consagração de certos geógrafos em detrimento de outros. "Quando a obra se mostrar dócil [aos valores dominantes], será chamada 'clássica”" (Costa Lima, 2006: 333), sentenciou Costa Lima a propósito do controle do imaginário a incidir sobre a Literatura. Seu raciocínio é integralmente válido para a geografia, inútil esclarecer. Nesse mesmo tom, desde que Walter Benjamin nos advertiu que o passado e o processo histórico devem estar abertos à inspeção permanente em nome da consciência política dos homens do presente (Benjamin, 2012 [1940]), cabe aos historiadores da geografia - mas não exclusivamente a eles - um incômodo constante em relação ao que acreditam saber sobre os clássicos. Assim, entendemos que a "aura de imortalidade" então aludida é apenas uma metáfora romântica e não uma cristalização da história das ideias. Do contrário, ela tenderia a reforçar ainda mais o eurocentrismo e seus "heróis" - o que não é o caso de On canonical geographies, bien entendu.

12 Outro bom debate levantado refere-se ao papel das coletâneas (Keighren et al., 2012: 299-302). Se os entendemos bem, nossas posições e as do artigo em questão são bastante convergentes. Ocorre que as preocupações iniciais das coletâneas, não raro associadas ao incremento do ensino de história da geografia, nem sempre possuem o efeito desejado, pois em certa medida acabam por contribuir para a canonização de 
determinado texto como se todo o pensamento do autor ali se concentrasse e, assim, desnecessário seria o aprofundamento junto aos originais. Entretanto, o problema parece residir menos nas coletâneas em si que na recepção que o campo geográfico faz desse gênero de publicação. Em um país atravessado por profundas desigualdades socioeconômicas como o Brasil, a aquisição de habilidades linguísticas evidentemente não pode ser concebida apenas na esfera intelectual. Quantos estudantes já não se interessaram por história da geografia mas atinaram que a questão idiomática seria um obstáculo e desistiram da área? Assim, as coletâneas possuem notório valor didático desde que não sejam tomadas como fins em si mesmo. Além disso, a escolha dos autores e artigos precisa ser objeto de suspeita, pois obedece tanto às inclinações políticoacadêmicas por parte dos organizadores quanto à atmosfera histórico-intelectual da época, tal como assinalamos sobre a recepção de Vidal de la Blache a partir da famosa coletânea Perspectivas da Geografia organizada pelo geomorfólogo neopositivista Antonio Christofoletti em plena ascensão das abordagens radicais (Christofoletti, 1982; Ribeiro, 2020). Em outras palavras, no rastro da estética da recepção (Costa Lima, 1979, 2010), caberá ao leitor, ao bom leitor, a consciência de que ele sempre será responsável por complementar a coletânea. Entre nós, as de Max. Sorre, Élisée Reclus e Friedrich Ratzel nos anos oitenta e noventa merecem ser estudadas detalhadamente em termos de agentes e temas envolvidos, desdobramentos no campo geográfico nacional e difusão maciça desses volumes - e da Coleção Grandes Cientistas Sociais em geral - em período de expansão universitária (Sorre, 1984; Reclus, 1985; Ratzel, 1990). Proposta como síntese do espírito da Coleção, a definição de "cosmopolitismo periférico" (Rodrigues, 2018) fornece ótimo ponto de reflexão para os interessados em circulação geopolítica do conhecimento e dos idiomas, por exemplo.

Outro tópico a ser destacado está na coragem com que On canonical geographies encarou a disseminação da língua inglesa e, de modo amplo, a "pejorativa influência da hegemonia anglo-americana nas publicações da geografia humana contemporânea" (Keighren et al., 2012: 305). Partindo de três colegas que possuem o inglês como principal idioma de trabalho (sendo que dois deles estão lotados em um dos principais departamentos de geografia da Europa, o da Royal Holloway University of London) e que assinaram um texto cuja bibliografia é composta majoritariamente de referências em inglês, a crítica incisiva a tudo aquilo que se perde por causa desse domínio monolinguístico e intelectual deve ser valorizada (vide o "desperdício da experiência" identificado por Santos [2007/2000] em sua crítica à modernidade) - inclusive por apontar a tradução de autores não-anglófonos como uma das possíveis saídas para interrogar tal hegemonia (Keighren et al., 2012: 309).

Não podemos esquecer que esse "regime" linguístico - para recuperar a potência política contida no exame das línguas e traduções por Naoki Sakai (Sakai, 2010; Sakai \& Mezzadra, 2014) - é recente na geografia brasileira e foi forjado no bojo da ascensão dos Estados Unidos como potência global a partir de 1945 e do inglês como idioma de negócios. Some-se a isto o papel jogado pelo approach neopositivista entre nós, pois os artigos que chegaram ao país eram majoritariamente escritos em inglês e foram traduzidos em bom número pelo IBGE através da Revista Brasileira de Geografia e do Boletim Geográfico entre 1966 e 1982 (Ribeiro, 2021). Atualmente, uma das iniciativas mais estimuladas e bem avaliadas pelos editais de fomento à pós-graduação em um país periférico como o Brasil, a chamada internacionalização tornou-se quase que sinônimo de publicar em inglês e tecer redes de intercâmbio preferencialmente com colegas e instituições anglo-saxões. De toda forma, tanto a face neoimperialista desse movimento 
quanto seus desdobramentos positivos precisam ser objeto de ponderação equilibrada $\mathrm{e}$ sensata a fim de não incorrermos em maniqueísmos e provincianismos de toda sorte. Afinal, a questão é bastante complexa, aflige acadêmicos de vários países e deve ser analisada sob os mais diversos ângulos (Gyuris, 2018; van Meeteren, 2019). Seja por motivos geracionais, ideológicos ou geopolíticos (este último no sentido da "colonização do imaginário" evocada por Quijano [2000]), o fato é que a geografia humana brasileira tem permanecido ilhada no conforto de seu próprio idioma quando se trata de divulgar suas pesquisas, muito embora continue a traduzir com regularidade - traço característico das línguas dominadas, grife-se (Casanova, 2015) - e sem consciência do que está sendo feito.

Assim, On canonical geographies acerta no alvo ao reconhecer tanto no passado (via Reclus, Kropotkin, Penck, Geddes e Ghisleri) quanto no presente (Claval, Ferretti e Davies, se nos for permitido listar três historiadores da geografia europeus que aprenderam uma língua dominada como o português) as virtudes políticas e científicas do multilinguismo. Em suas próprias palavras: "Os exemplos acima ilustram como o engajamento com textos canônicos multilíngues podem levar à redescoberta de redes esquecidas, historiografias alternativas e, assim, a novas maneiras de recontar o passado geográfico, mas também podem conduzir - argumentamos - a novas formas de envolvimento com o presente e, o que é mais significativo, a imaginar e moldar futuros possíveis" (Keighren et al., 2012: 306).

Concluindo, On canonical geographies não é uma defesa corporativa de um subcampo tido como primo pobre frente a ramos mais altivos como a geografia urbana ou a econômica, mas uma chamada crítica a ser ouvida no que diz respeito ao aperfeiçoamento da formação profissional do geógrafo, por exemplo, além de uma defesa da historicidade dos fenômenos espaciais contra um presentismo não raro superficial e pragmático. Esperamos que sua recepção no Brasil seja ativa, ou seja, capaz de fertilizar controvérsias em torno do passado, do presente e do futuro da geografia e não mais uma tradução a ser canonizada como mera legitimação acadêmica em um país periférico ainda bastante colonizado intelectualmente.

\section{BIBLIOGRAFIA}

Benjamin, Walter. Sobre o conceito da história. In: Benjamin, Walter. Magia e técnica, arte e política: ensaios sobre literatura e história da cultura. $8^{\mathrm{a}}$ ed. revista. São Paulo: Brasiliense, 2012 [1940], p. 241-252. Tradução de Sérgio Paulo Rouanet.

Bourdieu, Pierre. 0 poder simbólico. $9^{\mathrm{a}}$ ed. Rio de Janeiro: Bertrand Brasil, 2006 [1989]. Trad. de Fernando Tomaz. 311p.

Bourdieu, Pierre. Os usos sociais da ciência. Por uma sociologia clínica do campo científico. São Paulo: Unesp, 2004 [1997]. Tradução de Denice Barbara Catani. 86p.

Buarque de Holanda, Sergio. Raízes do Brasil. Edição comemorativa 70 anos. São Paulo: Companhia das Letras, 2006 [1936]. 447p. 
Capel, Horacio. Filosofía y ciencia en la geografía contemporánea. Barcelona: Barcanova, 1981. 509pp.

Casanova, Pascale. La langue mondiale. Traduction et domination. Paris: Seuil, 2015. 129p.

Chakrabarty, Dipesh. Provincializing Europe. Postcolonial thought and historical difference.

Princeton and Oxford: Princeton University Press, 2008 [2000]. 301p.

Christofoletti, Antonio (org.). Perspectivas da geografia. São Paulo: Difel, 1982. 156p. Vários tradutores.

Correia de Andrade, Manuel. Geografia, ciência da sociedade: uma introdução à análise do pensamento geográfico. São Paulo: Atlas, 1987. 143p.

Costa Lima, Luiz. Luiz Costa Lima: uma obra em questão. Organização de Dau Bastos. Rio de Janeiro: Garamond/FAPERJ, 2010. 406p.

Costa Lima, Luiz. História. Ficção. Literatura. São Paulo: Companhia das Letras, 2006. 434p.

Costa Lima, Luiz. Prefácio à $2^{\mathrm{a}}$ edição. A Literatura e o leitor: textos de estética da recepção. Seleção, coordenação e tradução de Luiz Costa Lima. 2. ed. revista e ampliada. São Paulo: Paz e Terra, 1979, p. 9-36.

Foucault, Michel. L'ordre du discours. Paris: Gallimard, 1971 [1970]. 82p.

Foucault, Michel. Orders of discourse. Social science information 10 (2), 1971 [1970], p. 7-30.

Translated by Rupert Swyer.

Foucault, Michel. L'ordine del discorso. I meccanismi sociali di controllo e di esclusione della parola, trad. Alessandro Fontana, Torino: Einaudi, 1972 [1970]. 98p.

Foucault, Michel. Diskursens ordning: installationsföreläsning vid Collège de France den 2 december 1970, översättning Mats Rosengren, Symposion, 1993 [1970]. 59p.

Gyuris, Ferenc. Problem or solution? Academic internationalization in contemporary human geography in East Central Europe. Geographische Zeitschrift, v. 106, n. 1, 2018, p. 38-49.

Jöns, Heike; Meusburger, Peter; Heffernan, Michael (Eds.). Mobilities of knowledge. Springer International Publishing, 2017. 303p.

Keighren, Innes; Abrahamsson, Christian; della Dora, Veronica. On canonical geographies. Dialogues in Human Geography, v. 2, n. 3, 2012, p. 296-312.

Latour, Bruno. Science in action. How to follow scientists and engineers through society. Cambridge, Massachusetts: Harvard University Press, 1987. 247pp.

Livingstone, David. Putting science in its place. Geographies of scientific knowledge. Chicago and London: The University of Chicago Press, 2003. 244p.

Meusburger, Peter; Livingstone, David; Jöns, Heike (Eds.). Geographies of science. Heidelberg: Springer, 2010.250p.

Mezzadra, Sandro; Sakai, Naoki. Introduction. Translation, n. 4 - Politics, spring, 2014, p. 9-29.

Mignolo, Water. Local histories/global designs: coloniality, subaltern knowledges, and border thinking. Princeton: Princeton University Press, 2000. 416pp.

Moreira, Ruy. O que é geografia? São Paulo: Brasiliense, 1980. 113pp.

Moraes, Antonio Carlos Robert. Geografia: pequena história crítica. 17. ed. São Paulo: Hucitec, 1995 [1981] 138pp. 
Naylor, Simon. Historical geography: knowledge, in place and on the move, Progress in Human Geography, v. 29, n. 5, 2005, p. 626-634.

Ophir, Adi; Shapin, Seven. The place of knowledge. A methodological survey. Science in context, v. 4, n. 1, 1991, p. 3-21.

Ortiz, Renato. Mundialização e cultura. São Paulo: Brasiliense, 1994. 234p.

Quijano, Aníbal. Coloniality of power and social classification. Journal of World-Systems Research, v. 6, n. 2, 2000, p. 342-386.

Ratzel, Friedrich. Ratzel. Organização de Antonio Carlos Robert Moraes. São Paulo: Ática, 1990. Tradução de Fátima Murad e Denise Bottman. 199p.

Reclus, Élisée. Reclus. Organização de Manuel Correia de Andrade. São Paulo: Ática, 1985.

Tradução de Maria Cecília França, Januário Francisco Megale e B.F. Ramiz Galvão. 200p.

Ribeiro, Guilherme. Translation of quantitative geography in the Brazilian journals: the cases of Boletim Geográfico (1966-1976) e Revista Brasileira de Geografia (1970-1982). In: Boris, M., Gyuris, F., Paulus, K. (eds.). Quantitative Geographies: new perspectives, scales, and receptions. New York and London: Routledge Forthcoming, 2021.

Ribeiro, Guilherme. Tradução e canonização na história da geografia: dois momentos da recepção de Vidal de la Blache no Brasil (1982 e 2020). Terra Brasilis (Nova Série), n. 14, 2020, p.1-9.

Ribeiro, Guilherme. Nos confins da tradução: deslocamentos de Paul Vidal de la Blache no Brasil (1943-2019). Boletim Goiano de Geografia, v. 40, 2020a, p. 1-28.

Ribeiro, Guilherme; Haesbaert, Rogério; Nunes Pereira, Sergio. Relendo Vidal: em busca de novos enfoques. In: Haesbaert, Rogério, Nunes Pereira, Sergio, Ribeiro, Guilherme. Vidal Vidais: textos de geografia humana, regional e política. Rio de Janeiro: Bertrand Brasil, 2012, p. 13-19.

Rodrigues, Lidiane Soares. Centralidade de um cosmopolitismo periférico: a "Coleção Grandes Cientistas Sociais" no espaço das ciências sociais brasileiras (1978-1990). Sociedade e Estado, v. 33, n.3, 2018, p. 675-708.

Said, Edward. Orientalismo: o Oriente como invenção do Ocidente. São Paulo: Companhia das Letras, 1990 [1978]. Tradução de Tomás Rosa Bueno. 370p.

Sakai, Naoki. Translation and the figure of border: toward the apprehension of translation as a social action. Profession, 2010, p. 25-34.

Santos, Boaventura de Sousa. A crítica da razão indolente: contra o desperdício da experiência. 6 . ed. São Paulo: Cortez, 2007 [2000]. 415p.

Secord, James. Knowledge in transit. Isis, v. 95, n. 4, 2004, p. 654-672.

Sodré, Nelson Werneck. Introdução à geografia: geografia e ideologia. Petrópolis: Vozes, 1976. 135p.

Sorre, Max. Sorre. Organização de Januário Francisco Megale. São Paulo: Ática, 1984. Tradução de Januário Francisco Megale, Maria Cecília França e Moacir Marques. 192p.

van Meeteren, Michiel. On geography's skewed transnationalization, anglophone hegemony, and qualified optimism toward an engaged pluralist future; A reply to Hassink, Gong and Marques. International Journal of Urban Sciences, v. 23, n. 2, 2019, p. 181-190.

Werner, Michaël; Zimmermann, Bénédicte. Penser l'histoire croisée : entre empirie et réflexivité. In : Werner, Michaël; Zimmermann, Bénédicte (sous la direction de). De la comparaison à l'histoire croisée. Paris : Seuil, 2004, p. 15-52. 


\section{RESUMOS}

O comentário a seguir identifica alguns dos principais aspectos do artigo On canonical geographies, com destaque para a problematização dos conceitos de clássico e canônico, os perigos de uma possível dicotomia entre eles e a necessidade de descolonizá-los. Além disso, trazemos alguns exemplos locais mostrando como tais conceitos ajudam a iluminar a história da geografia produzida e consumida no Brasil.

The following commentary addresses the main features of the paper On canonical geographies, emphasizing the definition of the concepts of classic and canonical and the dangers of a possible dichotomy between them, as well as the need to decolonise them. In addition to this, I bring some local examples showing how that concepts might shed light on the history of geography as it is written and read in Brazil.

Le commentaire suivant vise à identifier les principaux traits de l'article On canonical geographies, en soulignant les définitions des concepts de classique et de canonique, les dangers de les interpréter de façon dichotomique et le besoin de les décoloniser. En outre, à partir d'exemples locaux je montre comme ces concepts peuvent clarifier l'histoire de la géographie brésilienne.

El siguiente comentario identifica algunos de los aspectos principales del artículo Sobre geografías canónicas, destacando la problematización de los conceptos de clásico y canónico, los peligros de una posible dicotomía entre ellos y la necesidad de descolonizarlos. Además, traemos algunos ejemplos locales que muestran cómo tales conceptos ayudan a iluminar la historia de la geografía producida y consumida en Brasil.

\section{ÍNDICE}

Índice geográfico: Brasil

Palavras-chave: clássico, canônico, descolonização, história da geografia, Brasil Índice cronológico: Século XX, Século XXI

Mots-clés: classique, canonique, décolonisation, histoire de la géographie, Brésil Palabras claves: clásica, canónica, descolonización, historia de la geografía, Brasil Keywords: classic, canonical, decolonisation, history of geography, Brazil

\section{AUTOR}

\section{GUILHERME RIBEIRO}

Universidade Federal Rural do Rio de Janeiro, Departamento de Geografia, Programa de PósGraduação em Geografia, Laboratório Política, Epistemologia e História da Geografia (UFRRJ/ DGG/PPGGEO/LAPEHGE). E-mail: lapehge@gmail.com 